\title{
Creation and analysis of a novel chimeric promoter for the complete containment of pollen- and seed-mediated gene flow
}

\author{
Zongrang Liu $\cdot$ Changhe Zhou $\cdot$ Keqiang Wu
}

Received: 10 January 2008/Revised: 4 February 2008/Accepted: 17 February 2008/Published online: 4 March 2008

(C) Springer-Verlag 2008

\begin{abstract}
Effective containment of gene flow in transgenic plants requires a promoter that is highly specific for male and female gametes or tissues. Here, we report the creation of a novel pollen-, stigma- and carpel-specific (PSC) promoter through the fusion of the pollen-specific LAT52 and carpel-specific AGL5 enhancers to a stigmaspecific $S L G$ promoter. Gene expression analysis showed that fusion of the LAT52 enhancer to the $S L G$ promoter enables the latter to gain pollen-specific activity while the acquirement of carpel-specific activity requires the correct orientation of the inserted AGL5 enhancer in the PSC promoter, and only a forward- but not a reverse-oriented one is functional. The resulting $f P S C$ promoter, when fused to $D T$ $A$, generated at least three aberrant gynoecium phenotypes. Type I plants exhibited shortened stigmatic tissues, resembling plants containing the $D T-A$ gene controlled by the $S L G$ promoter. However, type II and III plants displayed partial or complete ablation of gynoecia, and were unable to support the reproductive process. Type II and III plants also produced severely perturbed anthers and pollen in comparison to type I or $S L G:: D T$-A plants, and transgenic pollen
\end{abstract}

Communicated by R. Schmidt.

Z. Liu ( $ه$ )

USDA-ARS, Appalachian Fruit Research Station,

2217 Wiltshire Road, Kearneysville, WV 25430, USA

e-mail: Zongrang.liu@ars.usda.gov

C. Zhou

Department of Biology, West Virginia University, Morgantown,

WV 26506-6057, USA

K. Wu $(\bowtie)$

Institute of Plant Biology, College of Life Science,

National Taiwan University, Taipei 106, Taiwan

e-mail: kewu@ntu.edu.tw grains were unable, when out-crossed with control plants, to pass the transgene to the next generation in all plants examined, indicating that they are selectively eliminated. This tissue-specific ablation or perturbation is highly specific, and does not compromise vegetative growth. Evidently, the $f P S C$ promoter faithfully acquires tissue specificity from the incorporated enhancers and promoter, and should have a practical application for transgene containment in non-fruit and -grain producing plant crops.

Keywords Tissue-specific enhancer . Chimeric promoter . Tissue ablation .

Gene flow and containment

\section{Introduction}

Concerns regarding pollen- and seed-mediated gene flow and potential food safety of transgenic crops are growing and spurring intense debates, which has a significant impact on grower and consumer confidence, acceptance and adoption of food derived from transgenic crops. A primary concern is that copious amounts of pollen derived from genetically modified (GM) crops could pollinate and hybridize with their wild relatives. It is also a concern that seeds released into the environment from transgenic crops could cause introgression of the transgene into the genome of a wild relative in subsequent generations (Snow 2002). Introgression of these superior traits into wild type plants or their close wild relatives through gene flow (Mikkelsen et al. 1996; Snow and Palma 1997; Ellstrand et al. 1999; Ellstrand 2001) could boost the fitness of their progenies, which could facilitate the evolution of more aggressive and invasive weeds or species (Snow 2002; Hall et al. 2000). This could potentially pose a major threat to biological 
diversity, ecosystem function and agricultural productivity (Li et al. 2004). Hence, properly containing and mitigating gene flow is of ecological, economical and environmental significance.

Diverse plant crops and species are of distinct economic value and each requires a specific containment strategy. For example, many crops produce edible seeds (e.g. maize, soybean, etc.) or fruits (e.g. apple, citrus) that serve as sources of food for human consumption, while others, such as forestry and ornamental species, serve different purposes and their fruit and seeds are of little economical value. The same gene containment method, such as reproductive sterility, would likely compromise the productivity of foodproducing crops but would surely benefit that of GM forestry or other non-food producing plants by conserving nutrients which are otherwise exhausted by growing fruit and seeds. Thus, distinct gene containment strategies are required to meet the special needs of each individual crop.

A few potential containment strategies for grain- and fruit-producing crops have been under extensive study. One of the strategies is to exploit the unique maternal inheritance of chloroplasts for the restriction of pollenmediated gene flow (Daniell 2002). Chloroplasts are known to pass their genome on to the next generation through female but not male gametes, which provides a natural containment for gene flow. Thus, a transgene integrated into the chloroplast genome of GM crops is passed on to the next generation only through female gametes, while male gametes remain free from the introduced transgene. As chloroplast transformation systems become available in cotton (Kumar et al. 2004b), carrots (Kumar et al. 2004a), tomato (Ruf et al. 2001), tobacco (Avni and Edelman 1991; Daniell et al. 1998) and rice (Khan and Maliga 1999), chloroplast-mediated transgene containment should be achievable in many agriculturally important crops.

Transgene mitigation offers an alternative approach that is based on the ecological principle that by reducing the fitness of transgene recipients in hybrids, the eventual extinction of all hybrids will result after a few generations (Gressel 1999). Accordingly, any gene that is positive or neutral to the crop but deleterious to hybrids and their progeny (such as dwarfing) would serve as a mitigating tool to weaken the fitness of the hybrids, leading eventually to the elimination of the hybrids from the wild population. An exquisite example of this is the observation that transgenic plants with an engineered dwarf phenotype are unable to compete for light with wild-type plants. As a consequence, most of them died or formed no flowers when grown in proximity to wild-type plants (Al-Ahmad et al. 2004)

Genetic use restriction technology (GURT) is based on repressible two-component systems (e.g. Barnase-Barstar) in which seeds produced by the plants are non-viable unless the plants are exposed to a specific activator molecule or stimulus. One example is the recoverable block of function (RBF) system, which relies on an integrated transgene that carries seed-specific Barnase, and heatinducible Barstar expression units (Kuvshinov et al. 2001). Escaped pollen from transgenic plants carrying RBF pollinates wild-type plants and produces seeds. These hybrid seeds, however, cannot germinate unless they are treated with a heat shock.

The tissue-specific gene excision approach proposed by Keenan and Stemmer (2002) is a comprehensive strategy to address the concerns of both gene flow and food safety of transgenic plants. The transformation vector can be designed such that all transgene components necessary for selection and crop improvement can be excised by "molecular scissors", in the pollen, seed and fruit tissues or in the early stage of floral initiation so that the derived pollen, fruit and seed are expected to carry no transgene except for a small residual DNA footprint. With the creation of a novel chimeric LoxPFRT site, Luo et al. (2007) have demonstrated that a transgene excision efficiency of up to $100 \%$ can be achieved in pollen or seeds when either Flp or Cre is specifically expressed. This study provides the first evidence that highly efficient tissue-specific transgene excision is achievable in plants.

Tissue-specific ablation of flowers or male and female gametes by a cytotoxic gene provides a direct and effective means to contain transgene flow for non-grain and -fruit producing plants such as ornamental, landscape and forestry species. The $D T-A$ gene coding for a ribosome inactivating protein (Palmiter et al. 1987), and Barnase gene coding for an extracellular ribonuclease that is inhibited by Barstar (Hartley 1988) have been used as effective genetic agents for engineering reproductive sterility in many different species (Beals and Goldburg 1997; Block and Debrouwer 1993; Block et al. 1997; Burgess et al. 2002; Gleba et al. 2004; Mariani et al. 1990, 1992). A similar approach has also been applied to gene containment in woody species such as Populus (Skinner et al. 2003; Wei et al. 2007) and birch trees (Lännenpää et al. 2005a, b; Lemmetyinen et al. 2001, 2004). However, a lack of tightly regulated floral organ- or gamete-specific promoters often leads to severe damage to non-targeted vegetative tissues in transgenic plants (Lännenpää et al. 2005a, b; Skinner et al. 2003; Wei et al. 2007), and an additional gene repression system is required to specifically repress the detrimental effects of the expressed cytotoxic gene product on vegetative tissues (Kobayashi et al. 2006; Wei et al. 2007). Hence, highly specific and tightly controlled, floral organ- or gamete-specific promoters are important for the 
successful containment of transgene flow without compromising vegetative growth. In this study, we report the creation of a novel chimeric promoter through an enhancer-promoter fusion approach and the characterization of its tissue specificity as well as its potential utility for gene containment in transgenic plants.

\section{Materials and methods}

Plasmid construction

A 410-bp $S L G$ stigma-specific promoter (Thorsness et al. 1993 ) isolated from plasmid pMKT11 was fused to $G U S$, Barnase and DT-A coding regions, respectively, to create $S L G:: G U S, S L G:: D T-A$ and $S L G:: B a r n a s e$ constructs. The $S L G:: B a r n a s e$ construct contained a copy of Tac-Barstar in order to neutralize the Barnase's detrimental effect on bacterial cells. A 440-bp LAT52 pollen-specific enhancer (Bate and Twell 1998) was amplified by PCR from tomato genomic DNA with a primer pair of LAT52U (5'gtcttctgtctgaagctttcgacatact- $\left.3^{\prime}\right)$ and LAT52L (5'-gagatatcaatatggtggagctattattgtgt- $\left.3^{\prime}\right)$, and fused to a minimal $35 \mathrm{~S}$ promoter $(-60)$ to create the $L A T p$ promoter. $L A T p$ was placed in front of the GUS gene to generate the LATp::GUS construct. To create a chimeric pollen- and stigma-(PS) specific promoter, the 440-bp LAT52 enhancer was inserted upstream to the $S L G$ promoter in $S L G: \because G U S$ to generate $P S:: G U S$. A 1,972 bp AGL5 carpel-specific promoter (Savidge et al. 1995) isolated from the Arabidopsis genome with a primer pair of AGL5U (5'-ctgtgacgt tggatatatacacaaaagcttgaa- $\left.3^{\prime}\right)$ and AGL5L2082 (5'-tccg ttcattggectaaggatcctattct- $3^{\prime}$ ) was inserted in front of $G U S$ and $D T-A$ coding regions, respectively, to create AGL5:: $G U S$ and AGL::DT-A constructs. The 1,885-bp AGL5 enhancer was amplified using a primer pair of AGL5U and AGL5L1996 (5'-tttcttttagaggaaagcttctttggaagt-3') and inserted in forward and reverse orientations upstream of the LAT52 enhancer in PS::GUS to create $f P S F:: G U S$ and $r P S F:: G U S$ fusions, respectively. The $d P S F:: G U S$ construct was created by restriction digestion-mediated deletion of a 200-bp region located at the $3^{\prime}$ end of the AGL5 enhancer in fPSC::GUS. fPFS::DT-A was made by replacing the GUS coding region in $f P S C: \because G U S$ with the $D T-A$ gene fragment isolated from pR2283. All gene fusions were based on the binary vector pBin 19 (Bevan 1984) and are illustrated in Fig. 1.

Plant material and transformation

Arabidopsis thaliana C10 (ecotype Columbia) was grown in a growth chamber ( $16 \mathrm{~h}$ of light and $8 \mathrm{~h}$ of darkness at $22^{\circ} \mathrm{C}$ ). Arabidopsis transformation was carried out as described previously (Clough and Bent 1998). Primary transformants $\left(\mathrm{T}_{0}\right)$ were selected on medium containing half-strength Murashige and Skoog (MS) salts (Sigma, St Louis, MO, USA) supplemented with $1 \%$ sucrose, $\mathrm{pH} 5.7$, $0.8 \%(\mathrm{w} / \mathrm{v})$ agar and $50 \mathrm{mg} / \mathrm{l}$ of kanamycin.

Histochemical GUS assay

GUS assays were performed according to the described protocol (Jefferson 1988). Arabidopsis tissue was incubated in a $0.5 \mathrm{mg} / \mathrm{ml}$ solution of 5-bromo-4-chloro-indolyl $\beta$-D-glucuronide (X-Gluc) in $100 \mathrm{mM}$ sodium phosphate buffer, $\mathrm{pH} 7.0$ at $37^{\circ} \mathrm{C}$ overnight, followed by washing with $70 \%$ ethanol to remove the chlorophyll.

Pollen survival assay

Survival of pollen grains was indicated by intracellular retention of fluorescein produced by enzymatic hydrolysis of fluoroscein diacetate (Sigma, St Louis, MO, USA). Fluorescein diacetate was prepared in acetone $(2 \mathrm{mg} / \mathrm{ml})$ and diluted in sterile distilled water at a concentration of $0.2 \mathrm{mg} / \mathrm{ml}$. Pollen grains were dispersed in a drop of fluorescein diacetate solution on a microscope slide and incubated for about $10 \mathrm{~min}$. The image was captured using an Olympus florescent microscope.

Plant pollination

Arabidopsis flower buds with emerging petals (white tip) were opened with the tip of a pair of forceps between the petals and sepals, and immature anthers were removed. After 2-3 days, the stigmas in the emasculated flowers were pollinated with pollen from open, mature flowers twoto three times.

\section{RT-PCR analysis}

Total RNA was isolated from young flower buds using the RNeasy Plant Mini Kit (Qiagen), and was treated with DNase to remove contaminating genomic DNA using the DNA-free kit (Ambion, Austin, TX, USA). Twenty nanograms of total RNA was used for RT-PCR amplification using the RT-PCR kit (Qiagen) with primer pairs DTAU363 (cttcgtaccacgggactaaactggttatgt) and DTAL800 (aagttctacgcttaac getttcgcetgt) for DT-A, and EF1F (gcactgtcattgatg ctcc) and EF1R (gtcaagagcctcaag gagag) for EFIa. Amplification cycles included $45^{\circ} \mathrm{C}$ for $30 \mathrm{~min}$ for the reverse transcription step and $95^{\circ} \mathrm{C}$ for $15 \mathrm{~min}$ for the activation of Hotstart Taq DNA polymerase, followed by 27 cycles of $94^{\circ} \mathrm{C}$ for $1 \mathrm{~min}, 48-50^{\circ} \mathrm{C}$ for $1 \mathrm{~min}$, and $72^{\circ} \mathrm{C}$ for $2 \mathrm{~min}$. 
A

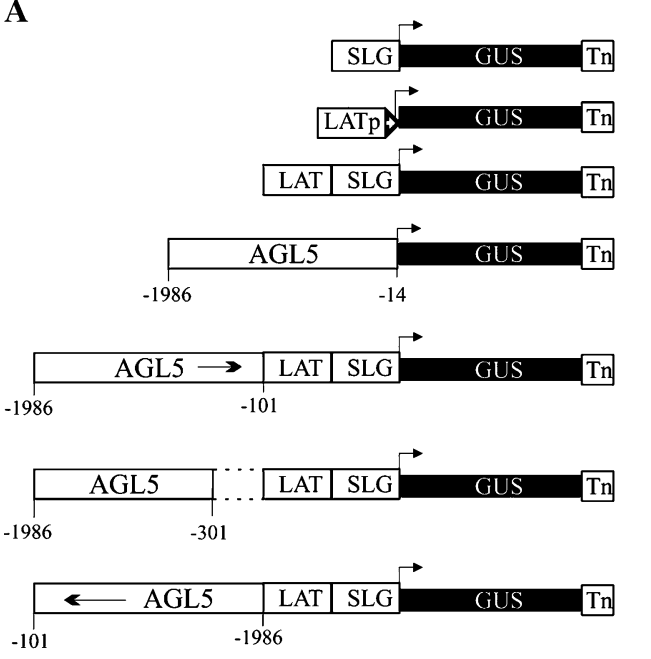

B

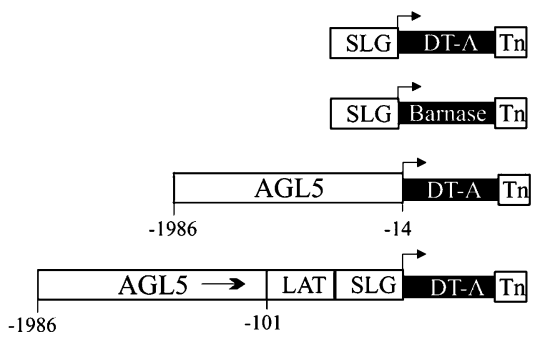

Fig. 1 Construction and testing of a series of tissue-specific promoters. Promoter construction and GUS fusion (a). Brassica stigmaspecific promoter $S L G$, pollen-specific promoter $L A T p$ containing the tomato LAT52 enhancer fused to the 60-bp minimal CaMV 35S promoter (marked as a filled trangle), pollen- and stigma-specific $P S$ promoter, and carpel-specific promoter AGL5 were placed in front of the $G U S$ coding region, respectively. Promoters $f P S C$ and $r P S C$ were identical except for the orientation of the AGL5 enhancer. Promoter $d P S C$ was derived from $f P S C$ by the deletion of a 200-bp fragment at the $3^{\prime}$ end of the AGL5 enhancer as indicated by dashed dots. Promoter-cytotoxic gene fusion (b). The promoters SLG, AGL5 and

\section{Results}

Verification of tissue-specific promoters in transgenic Arabidopsis

Engineering complete sterility for containing transgenes requires a promoter specific for male and female tissues or gametes. However, such a promoter is rarely available in nature. Since promoters specific for pollen, stigmas or carpels have been reported in many plant species, combining these promoter elements together through an enhancerpromoter fusion would generate an ideal promoter to meet the needs of transgene containment. The Brassica SLG promoter is specific for stigmatic and tapetum tissues and $S L G$-driven expression of $D T-A$ generated male and female
Tissue-specific gene expression and visible retardation/ablation

$\begin{array}{cc}\text { Anther } \\ \text { Stigma } & \text { and pollen } \\ \end{array}$

$S L G:: G U S$

LATp::GUS

$P S:: G U S$

AGL5::GUS

fPSC::GUS

$d P S C:: G U S$

$+\quad-/+\quad$ -

$r P S C:: G U S$

$S L G:: D T-A$

SLG::Barnase

$A G L 5:: D T-A$

$f P S C:: D T-A$

fPSC were fused to DT-A or Barnase, or both genes. The direction of transcription is indicated by arrows above the genes. The orientation, start and end positions of the AGL5 enhancer as well as its derivative in the PSC promoter are marked by arrows or numbers relative to the ATG start codon. Results of tissue-specific gene expression and perturbation/ablation are summarized in the right panel. GUS: Escherichia coli $\beta$-glucuronidase; DT-A: Diphtheria toxin A chain; Barnase: Bacillus amyloliquefaciens extracellular ribonuclease; Tn: the terminator of nopaline synthase gene. pBin 19 served as backbone vector for all constructs (Bevan 1984)

sterility but it is reversible (Thorsness et al. 1993), indicating that it lacks adequate strength for irreversible tissue retardation. The pollen-specific LAT52 enhancer from tomato (Bate and Twell 1998) and carpel-specific AGL5 enhancer from Arabidopsis (Flanagan et al. 1996; Roeder et al. 2003; Savidge et al. 1995) have been very well characterized and could serve as potential elements for reinforcing the $S L G$ promoter's specificity in pollen and carpel tissues. To test this possibility, we first tested and verified the reported tissue specificity of these promoters in plants through GUS fusions (Fig. 1a). Histochemical staining revealed that 19 of 26 $S L G: \because G U S$ lines were positive for GUS in stigmatic tissue (Fig. 2a). Earlier studies also showed that the $S L G$ promoter has additional weak activity in tapetum tissue and the $S L G$ promoter-mediated expression of $D T-A$ specifically 
perturbed tapetum tissue development, which led to male sterility (Kandasamy et al. 1993; Thorsness et al. 1993). Similarly, AGL5 promoter activity in carpel tissues was confirmed in 17 of 20 AGL5::GUS lines (Fig. 2e), which is in agreement with earlier findings that AGL5 is broadly expressed in the gynoecium in stage 10 flowers and is specifically limited to the valve margins and developing ovules through stage 17 (Flanagan et al. 1996; Roeder et al. 2003). To confirm tissue specificity of the LAT52 enhancer, we first created a functional LATp promoter by fusing the LAT52 enhancer to a 60-bp minimal $35 \mathrm{~S}$ promoter (Fig. 1a). Of 32 LATp-GUS lines, 30 showed positive GUS staining in anthers (Fig. 2b) and pollen (Fig. 2c). Taken together, our results confirmed the tissue specificity of the promoters and enhancers we cloned.
Creation and testing of the pollen-, stigma- and carpelspecific promoter

To create the pollen-, stigma- and carpel (PSC) promoter, we performed a stepwise fusion of the LAT52 and AGL5 enhancers to the $S L G$ promoter. The $L A T 52$ enhancer was first inserted upstream of the $S L G$ promoter to create a pollen- and stigma-specific (PS) promoter (Fig. 1a). Thirteen of eighteen PS::GUS lines were positive for GUS in stigmatic tissues, anthers and pollen but not vegetative tissues (Fig. 2d), indicating that the $P S$ promoter acquires additional pollen specificity from the LAT52 enhancer. To enable the $P S$ promoter to gain additional carpel tissue specificity, an approximately 1.9-kb AGL5 enhancer fragment was inserted upstream of the $P S$ promoter in forward
Fig. 2 Analyses of promoter activity in transgenic Arabidopsis. Histochemical GUS staining analysis was performed in stigmas (a) of $S L G: \because G U S$, anthers (b) and pollen grains (c) of LATp::GUS, stigmas and anthers (d) of $P S: \because G U S$, carpels (e) of $A G L 5:: G U S$, anthers, stigmas and carpels (f) of fPSC::GUS, anthers and stigmas $(\mathbf{g})$ of $r P S C:: G U S$, and anthers and stigmas (h) of $\mathrm{d} P S C: \because G U S$ plants. GUS staining of flowers from empty vector $p$ Bintransformed plants is shown as a control (i)
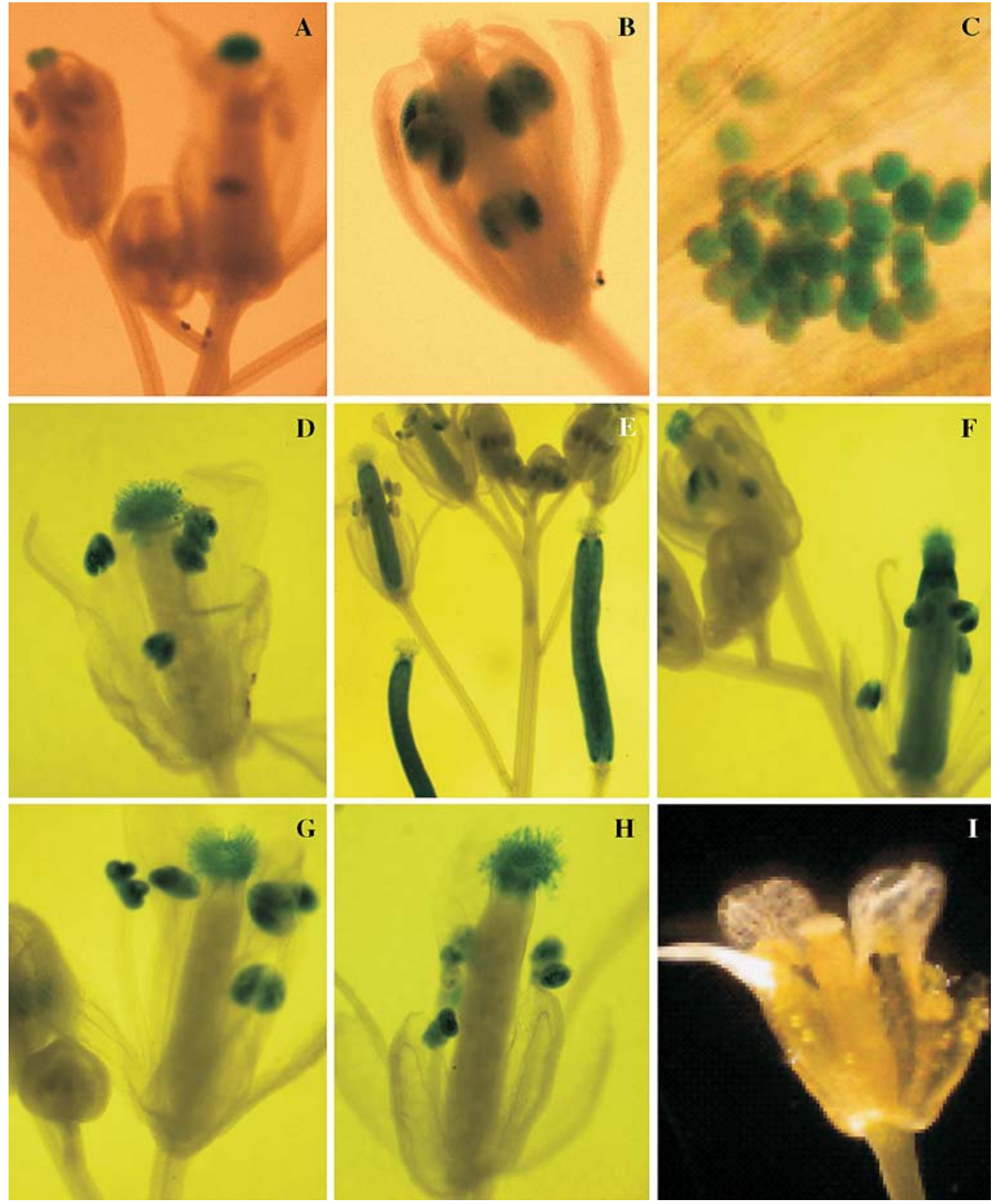
and reverse orientations to create $P P S C$ and $r P S C$ promoters, respectively (Fig. 1a). Of 26 fPSC::GUS lines, 12 showed GUS expression in anthers and stigmas, as well as carpels, particularly in stage 10 onward flowers (Fig. 2f). Surprisingly, 20 of 23 rPSC::GUS lines displayed positive GUS expression only in anthers and stigmas but not in carpels (Fig. 2g). These results indicate that only the forward-oriented AGL5 enhancer inserted in the PSC promoter was able to penetrate and express its activity in transgenic plants. These results also suggest that a core enhancer region could be located near the $3^{\prime}$ end of the $A G L 5$ enhancer fragment, and a reverse orientation of the $A G L 5$ enhancer fragment in the $r P S C$ promoter likely positions the core enhancer region distal to the $S L G$ promoter's transcription initiation sites, which might attenuate or prevent the AGL5 enhancer activity in the promoter. To test this possibility, we deleted an approximately $200 \mathrm{bp}$ region located at the $3^{\prime}$ end of the AGL5 fragment in $P P S C$ to create a $d P S C$ promoter (Fig. 1a). All $20 d P S C:: G U S$ lines lost GUS expression in carpels but not in stigmas and anthers (Fig. 2h), confirming that this $200 \mathrm{bp}$ region is essential to the $A G L 5$ enhancer.

Tissue-specific ablation by $f P S C$-directed expression of $D T-A$

Barnase and DT-A have been widely used for cell and tissue ablation and engineering of reproductive sterility in plants (Mariani et al. 1990; Thorsness et al. 1993). To compare their efficiency, we made $S L G:: D T-A$ and $S L G:: B a r n a s e$ fusions (Fig. 1b) and analyzed their effects on transgenic plants. Over $60 \%$ of Arabidopsis lines transformed with either of the gene fusions showed very similar phenotypes: delayed anther dehiscence, reduced pollen production and perturbed anther morphology (Fig. 3f) and self sterility (Table 1). The most obvious feature was the stigmatic tissues with shortened papillae cells (Fig. 3d, e) compared to those in vector-transformed wild-type flowers (Fig. 3b). However, plant growth and development, as well as flower structure, were not affected at all. These phenotypes are consistent with those reported in a previous study (Thorsness et al. 1993). The DT-A and Barnase genes appear to be functionally indistinguishable in tissue retardation and ablation. For the sake of convenient cloning, we chose $D T-A$ for the remaining analyses because the presence of the Barnase gene poses a difficulty for cloning in bacterial cells (Beals and Goldburg 1997).

The $f P S C: \because D T-A$ and AGL5::DT-A fusions were constructed and tested for tissue-specific perturbation and ablation (Fig. 1b). The AGL5::DT-A plants gave rise to two ablated gynoecium phenotypes. The first phenotype exhibited underdeveloped and bent gynoecia without style tissue, which was observed in 5 of 17 lines (Fig. 3g). The
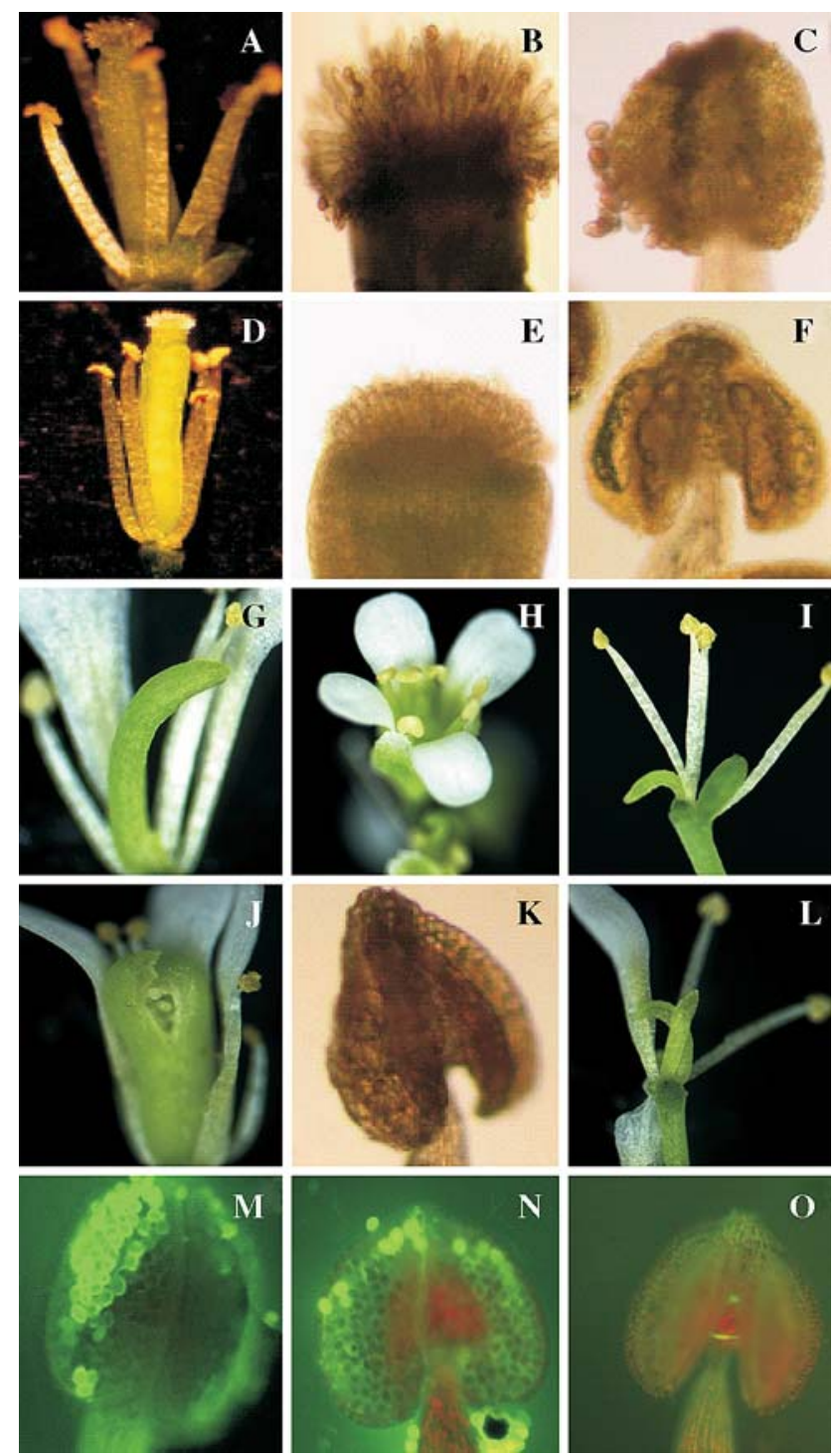

Fig. 3 Tissue-specific perturbation and ablation in transgenic plants. Wild-type flower (a), stigmas (b) and anthers (c) observed in a pBintransformed wild-type plant; mildly perturbed flower (d), stigmatic tissue (e) and anther (f) in $S L G:: D T-A$ plants; perturbed gynoecium with ablation of style (g) and absence of gynoecium $(\mathbf{h}, \mathbf{i})$ in $A G L 5:: D T-A$ plants; gynoecium with ablated style and unfused apex (j), severely perturbed anther (k) and absence of gynoecium (l) in $f P S C:: D T-A$ plants. Pollen viability was assayed by fluorescent staining of anthers from $p B i n(\mathbf{m})$, type I $S L G-D T-A$ (n) and type II fPSC::DT-A (o) plants

second phenotype showed an absence of gynoecia in 8 of 17 lines (Fig. 3h). In these plants, gynoecia were replaced by two leaf-like structures (Fig. 3i) that appear to represent two perturbed carpel residue tissues because the gynoecium in Arabidopsis is formed by the congenital fusion of two carpels. However, these plants displayed normal vegetative growth and development (data not shown). The ablated phenotypes are consistent with the demonstrated AGL5 tissue specificity (Fig. 2e; Flanagan et al. 1996; 
Table 1 Pollination analysis of transgene inheritance

\begin{tabular}{|c|c|c|c|}
\hline & \multicolumn{3}{|c|}{ Pollination and cross } \\
\hline & Fertile & $n$ & $\operatorname{Kan}^{R}$ \\
\hline \multicolumn{4}{|l|}{ Self-cross } \\
\hline Wild type (Wt) & 98 & 100 & 0 \\
\hline$S L G: \because D T-A$ & 0 & 100 & 0 \\
\hline$f P S C: \because D T-A$ & 0 & 100 & 0 \\
\hline \multicolumn{4}{|l|}{ Outcross } \\
\hline$[\mathrm{Wt}]+\times[S L G:: D T-A] \widehat{0}$ & 29 & 50 & 29 \\
\hline$[\mathrm{Wt}]$ 우 $\times[f P S C: \because D T-A] \widehat{\delta}$ & 4 & 54 & 0 \\
\hline
\end{tabular}

In self-crosses, 100 flowers each from three wild type, SLG::DT-A(type I phenotype), and $f P S C: \because D T$ - $A$ - (type II phenotype) transformed lines, respectively, were chosen for analyses. Successful pollination and fertilization was judged by the production of viable siliques and seeds. Outcrosses were performed by pollinating flowers of the wild type plants with pollen from the chosen three lines of $S L G:: D T-A$ type I and $f P S C:: D T-A$ type II plants, respectively. The $\mathrm{F}_{1}$ seeds from viable siliques were harvested and germinated on selection media containing $50 \mathrm{mg} / \mathrm{l}$ kanamycin. Any seedlings from each cross that showed kanamycin resistance in the $F_{1}$ population were scored as a resistant cross

Roeder et al. 2003). As expected, fPSC::DT-A plants displayed perturbed anthers and ablated gynoecia with a range of severities. Collectively, at least three types of perturbed gynoecia were observed. The type I phenotype displaying shortened stigmatic tissues was observed in 16 of 32 lines, and this phenotype resembled that of $S L G:: D T-A$ plants (Fig. 3d, e). The type II phenotype with complete ablation of style tissue and an unfused apex in the gynoecium (Fig. 3j) was observed in 5 of 32 lines. The type III phenotype with no visible gynoecia, which had been replaced by two leaf-like tissues, was observed in 4 of 32 lines (Fig. 31), and represented the most severe ablated phenotype. Type II and III phenotypes were very much like those observed in AGL5::DT-A plants (Fig. 3g-i), and were unable to support pollination or fertilization processes. Type II and III plants also exhibited similarly perturbed anthers (Fig. 3k), which are morphologically more severely malformed than those present in either type I or $S L G:: D T$ $A$ plants (Fig. 3f). Type II and III anthers produced and released very few viable pollen grains (Fig. 3o) in comparison to the abundant ones in anthers of pBintransformed wild type plants (Fig. $3 \mathrm{~m}$ ) and countable ones in $S L G:: D T-A$ or type I plants (Fig. 3n). The transgenic plants with all three types of retarded or ablated gynoecia were self sterile and did not produce viable siliques and seeds (Fig. 4b-d; Table 1) in comparison to the control transformed plants (Fig. 4a), but displayed a robust and prolonged vegetative growth that continued growing for up to 4 months (Fig. 4e, f), while the control transformed wild-type plants lasted approximately 2 months (Fig. $4 \mathrm{~g}$ ). RT-PCR analysis showed that a 450-bp DT-A transcript was consistently detected in flower tissues from all three types of $f P S C:: D T-A$ as well as $S L G:: D T-A$ plants, respectively, but not in control transformed plants (Fig. 5).

Sterility generated by $f P S C:: D T-A$ prevented transgene flow events

Complete containment of seed- and pollen-mediated gene flow cannot be achieved unless male and female gametes or organs are irreversibly perturbed or ablated. Type II and III $f P S C:: D T-A$ plants, due to the ablated style or gynoecium, were unable to support any pollination events and could not mediate gene flow through female gametes. Despite the fact that pollen viability was almost compromised in type II and III fPSC::DT-A plants as judged by fluorescent staining (Fig. 3o), whether transgenic pollen was still able to function as a gene flow carrier remains unknown. To address these questions, we chose three $f P S C: \because D T$-A lines with a type II phenotype for performing self-crossing and out-crossing analyses. As a comparison, we also chose three $S L G:: D T-A$ lines with a type I phenotype and three wild-type plants for the same crossing analyses. Table 1 shows that both the chosen SLG::DT-A and fPSC::DT-A lines were self sterile with the production of no viable siliques in 100 self-crossed flowers examined, while $98 \%$
Fig. 4 fPSC::DT-A plant reproduction and growth phenotypes. Six-week-old pBintransformed control plants dispayed regular fertilized siliques (a) and growth termination (g) while the same aged $f P S C:: D T-A$ plants showed a self sterile phenotype with unfertilized silique residues in type I (b), type II (c) and type III (d) as well as continuing flowering and vegetative growth in type II (e) and type III (f) lines
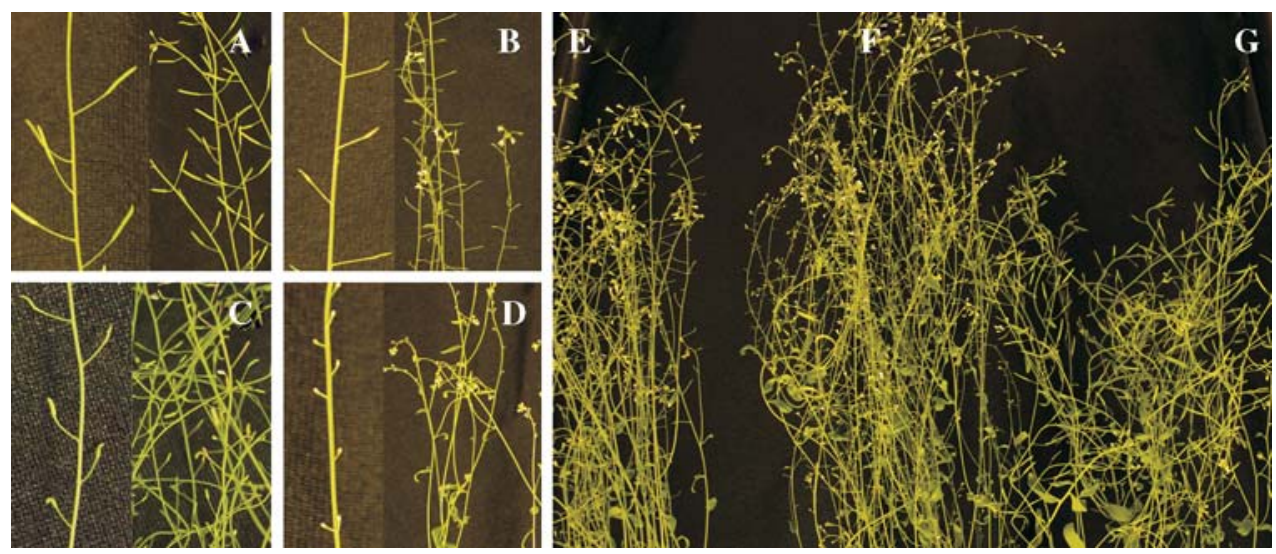


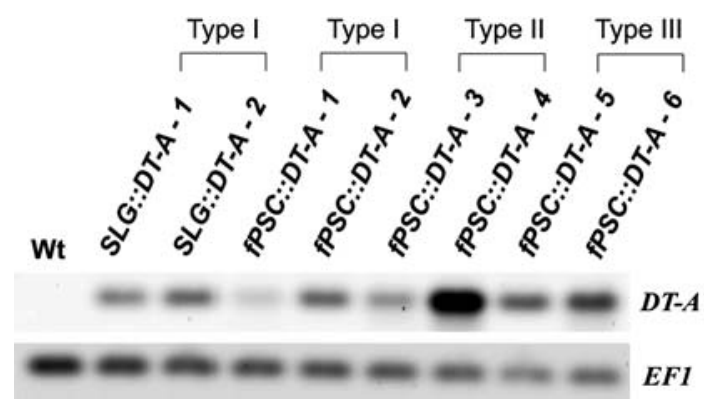

Fig. 5 RT-PCR analysis of gene expression in transgenic plants. RTPCR was performed for the analysis of DT-A expression using RNA samples isolated from floral tissues of one pBin-transformed (Wt), two $S L G:: D T-A$, and six $f P S C:: D T-A$ transgenic lines with distinct retarded flower phenotypes. Expression of the gene coding for elongation factor $(E F 1 a)$ served as an internal control

of self-crossed wild-type flowers produced normal siliques and seeds. In out-crossing analyses, 29 of 50 outcrosses in which the wild-type plants were pollinated with pollen from three $S L G:: D T-A$ plants produced siliques and seeds. About $15-40 \%$ of $\mathrm{F}_{1}$ seedlings from each cross could root and grow normally in media containing kanamycin, indicating that the kanamycin resistance gene, NPT-II, was successfully transmitted into the control wild-type plants via pollen from the $S L G-D T-A$ lines. This is also consistent with an earlier report (Thorsness et al. 1993). Although 4 of 54 outcrosses in which the wild-type plants were pollinated with pollen from the three type II $f P S C: \because D T-A$ lines produced siliques and seeds, none of the derived $\mathrm{F}_{1}$ seedlings showed resistance to kanamycin, as judged by the observation of seedlings with albino cotyledons and stunted roots in kanamycin-containing media. This indicates that transgenic pollen produced in the type II fPSC: $: D T-A$ plants failed to pollinate and transmit the transgene into the wild-type plants.

\section{Discussion}

Complete containment of transgene flow in transgenic plants is largely dependent on the elimination of gene flow carriers such as pollen, fruit and seeds by irreversible ablation or perturbation of male and female organs or gametes. Although several approaches have been developed to address this, most of them are limited to the specific eradication of either male gametes or tissues (Beals and Goldburg 1997; Block and Debrouwer 1993; Block et al. 1997; Mariani et al. 1990; Mariani et al. 1992), but specific elimination of both male and female gametes or tissues without compromising vegetative tissues remains challenging in large part because of the lack of desired promoters. The present study presents a new approach for creating novel chimeric promoters through enhancer- promoter fusion. The resulting promoter is specific for pollen, stigmatic and carpel tissues and its mediated expression of a cytotxic gene can specifically perturb or ablate the targeted tissues without compromising vegetative growth.

The $P P S C$ promoter acquires the desired tissue specificity from the incorporated enhancer elements. This is supported by two lines of evidence. First, as revealed by GUS expression analysis, the $F P S C$ promoter gains additional tissue specificity in pollen and carpels (Fig. 2f). Second, as revealed by tissue ablation analysis, $P$ PSC promoter-mediated DT-A expression can completely or partially ablate gynoecium tissue (Fig. 3j, 1), severely perturb anthers (Fig. 3k) and compromise pollen viability (Fig. 3o) compared to $S L G:: D T-A$-mediated expression (Fig. 3d-f, n). The lack of GUS expression in non-targeted tissues, and the observed integrity of vegetative growth in $f P S C: \because D T-A$ plants further confirms that the $P P S C$ promoter activity is specifically restricted to targeted floral tissues, and the fusion of multiple flower-specific enhancers together does not alter, or interfere with the individual element's specificity.

Previous reports have shown that flower-specific ablation using various promoters often generated diverse phenotypes ranging from mild to severe retardation (Lännenpää et al. 2005a, b; Lemmetyinen et al. 2001, 2004; Nilsson et al. 1998; Skinner et al. 2003; Wei et al. 2007). fPSC promotermediated flower-specific ablation also produced at least three different gynoecium phenotypes. The type I phenotype with shortened papillae cells in stigmatic tissue resembles that commonly observed in $S L G:: D T-A$ plants (Fig. 3d, e, k). Consistent with earlier studies (Thorsness et al. 1993), this phenotype is self sterile but outcross fertile (Table 1). Therefore, the type I phenotype observed in fPSC::DT-A lines primarily results from the stigma-specific tissue specificity of the base $S L G$ enhancer/promoter in the fPSC. Type II and III plants displayed perturbed gynoecia with different severities (Fig. 3j, 1), and are absolutely female sterile because of the lack of stylar tissue. Type III represents the strongest phenotype with no visible gynoecium except for two leaf-like tissues (Fig. 31) that presumably represent two residual carpels retarded at an early stage of development. The type II and III phenotypes resemble two phenotypes observed in AGL5::DT-A lines (Fig. $3 \mathrm{~g}-\mathrm{i}$ ). Since the $A G L 5$ promoter is specific in carpel and carpel margin tissue (Flanagan et al. 1996; Savidge et al. 1995; Roeder et al. 2003) that gives rise to placentae, ovules, septa, abaxial repla, and the majority of stylar and stigmatic tissue (Liu et al. 2000), the activity of the AGL5 enhancer in the $P P S C$ promoter likely contributes to both type II and III phenotypes observed in $f P S C:: D T$-A plants.

The fact that the $P S C$ promoter with a forward-oriented but not a reverse-oriented AGL5 enhancer fragment gains carpel-specific expression (Fig. 2f, g) indicates that AGL5 
enhancer function is orientation-dependent, which could be better explained by the distance of the inserted enhancer to the transcriptional start sites (TSS) provided by the $S L G$ base promoter (Fig. 1a). The inserted AGL5 fragment, which is approximately $1.9 \mathrm{~kb}$ in size, may bear a core enhancer element near its $3^{\prime}$ end, and the reverse orientation of the fragment accordingly positions the core enhancer element distal to the promoter's TSS region, which likely poses a physical distance barrier to block or attenuate penetration of AGL5 enhancer activity. Consistent with this speculation, the deletion of a 200-bp region at the $3^{\prime}$ end of the AGL5 fragment in the $P P S C$ promoter completely abolishes carpel-specific GUS expression in $d P S C:: G U S$ plants (Fig. 2h), indicating that the AGL5 $3^{\prime}$ region is critical. Despite the conventional wisdom that enhancer activity is independent of distance and orientation, the evidence to support a distance- and orientationdependent enhancer has also been reported for the immunoglobulin heavy chain $(\operatorname{IgH})$ enhancer in mammalian cells (Collins et al. 2006). Similarly, the fact that gene activation by the CaMV35S enhancer, one of the strongest ones characterized in plants is observed only within a $3.8-\mathrm{kb}$ region but not beyond (Weigel et al. 2000), also supports the distance-dependent action of enhancers in plant cells.

The pollen-specific LAT52 enhancer incorporated into the $f P S C$ promoter likely contributes to permanently perturbing pollen viability and pollination ability in $f P S C: \because D T$ $A$ plants. Two lines of evidence support this conclusion. First, anthers and pollen in type II and III $f P S C: \because D T-A$ plants displayed severe retardation as judged by anther morphology (Fig. 3k) and pollen viability (Fig. 3o) compared to type I or $S L G:: D T$-A plants (Fig. $3 \mathrm{f}, \mathrm{n}$ ) and controltransformed wild type plants (Fig. 3c, m). Second, genetic crosses showed that no transgenic pollen from the selected type II plants was, when out-crossed, able to pollinate and transmit the transgene into wild-type plants, indicating that transgenic pollen containing the $f P S C: \because D T-A$ transgene has completely lost its viability. Our results are consistent with an earlier work in which LAT52-directed DT-A expression was able to specifically kill transgenic pollen in most cases, as well as to indiscriminately eliminate all pollen production in some cases (Twell 1995).

Taken together, we present a new strategy for creating a $P S C$ promoter with novel tissue specificity which is rarely available in nature and $P P S C$-directed expression of $D T-A$ can completely prevent gene flow through selective elimination of male and female tissues or gametes that carry a transgene. Since a suite of genes involved in self incompatibility, pollination events and fruit development are found to be highly conserved for their function and tissue specificity across all plant taxa (Dwyer et al. 1994; Lee et al. 1994; Nasrallah and Nasrallah 1993; Gasser et al. 1989; Nasrallah et al. 1988), isolating these regulatory elements and fusing them together for the creation of various promoters with similar tissue specificity will be of importance for precisely and specifically containing transgene flow in a wide range of species, including ornamental, landscaping, forestry and bioenergy crops whose fruits and seeds are of little ecomonic value. Importantly, this strategy can be used for creating any promoter with desired tissue specificity to meet various research and industrial needs.

Acknowledgments We thank Dennis Bennett and Lin Zhang for the help with generating transgenic plants, Dr. June Nasrallah for providing SLG13 promoter and Dr. Stacy Singer for critical reading of the manuscript. This work was supported by a grant from US Department of Agriculture (2006-03701) to ZL.

\section{References}

Al-Ahmad H, Galili S, Gressel J (2004) Tandem constructs to mitigate transgene persistence: tobacco as a model. Mol Ecol 13:697-710

Avni A, Edelman M (1991) Direct selection for paternal inheritance of chloroplasts in sexual progeny of Nicotiana. Mol Gen Genet 225:273-277

Bate N, Twell D (1998) Functional architecture of a late pollen promoter: pollen-specific transcription is developmentally regulated by multiple stage-specific and co-dependent activator elements. Plant Mol Biol 37:859-869

Beals TP, Goldburg RB (1997) A novel cell ablation strategy blocks tobacco anther dehiscence. Plant Cell 9:1527-1545

Bevan M (1984) Binary Agrobacterium vectors for plant transformation. Nucl Acids Res 12:8711-8721

Block M, Debrouwer D (1993) Engineered fertility control in transgenic Brassica napus L: histochemical analysis of anther development. Planta 189:218-225

Block M, Debrouwer D, Moens T (1997) The development of a nuclear male sterility system in wheat: expression of the barnase gene under the control of tapetum specific promoters. Theor Appl Genet 95:125-131

Burgess DG, Ralston EJ, Hanson WG, Heckert M, Ho M, Jeng T, Palys JM, Tang K, Gutterson N (2002) A novel, two-component system for cell lethality and its use in engineering nuclear malesterility in plants. Plant J 31:113-125

Clough SJ, Bent AF (1998) Floral Dip: a simple method for Agrobacterium-mediated transformation of Arabidopsis thaliana. Plant J 16:735-743

Collins C, Azmi P, Berru M, Zhu X, Shulman MJ (2006) A weakened transcriptional enhancer yields variegated gene expression. PLoS One $1: \mathrm{e} 33$

Daniell H (2002) Molecular strategies for gene containment in transgenic crops. Nat Biotechnol 20:581-586

Daniell H, Datta R, Varma S, Gray S, Lee SB (1998) Containment of herbicide resistance through genetic engineering of the chloroplast genome. Nat Biotechnol 16:345-348

Dwyer KG, Kandasamy MK, Mahosky DI, Acciai J, Kudish BI, Miller JE, Nasrallah ME, Nasrallah JB (1994) A superfamily of $S$ locus-related sequences in Arabidopsis: diverse structures and expression patterns. Plant Cell 6:1829-1843

Ellstrand NC (2001) When transgenes wander, should we worry? Plant Physiol 125:1543-1545

Ellstrand NC, Prentice HC, Hancock JF (1999) Gene flow and introgression from domesticated plants into their wild relatives. Annu Rev Ecol Syst 24:217-242 
Flanagan CA, Hu Y, Ma H (1996) Specific expression of the AGL1 MADS-box gene suggests regulatory functions in Arabidopsis gynoecium and ovule development. Plant J 10:343-353

Gasser CS, Budelier KA, Smith AG, Shah DM, Fraley RT (1989) Isolation of tissue-specific cDNA from tomato pistils. Plant Cell $1: 15-24$

Gleba Y, Marillonnet S, Klimyuk V (2004) Design of safe and biologically contained transgenic plants: tools and technologies for controlled transgene flow and expression. Biotechnol Genet Eng Rev 21:325-367

Gressel J (1999) Tandem constructs: preventing the rise of superweeds. Trends Biotechnol 17:361-366

Hall L, Topinka K, Huffman J, Davis L, Allen A (2000) Pollen flow between herbicide-resistant Brassica napus is the cause of multiple-resistant B. napus volunteers. Weed Sci 48:688-694

Hartley RW (1988) Barnase and Barstar: expression of its cloned inhibitor permits expression of a cloned ribonuclease. J Mol Biol 202:913-915

Jefferson R (1988) Plant reporter genes: the GUS gene fusion system. In: Setlow JK, Hollaender A (eds) Genetic engineering: principles and methods. Plenum Press, New York, pp 247-263

Kandasamy MK, Thorsness MK, Rundle SJ, Goldberg ML, Nasrallah JB, Nasrallah ME (1993) Ablation of papillar cell function in Brassica flowers results in the loss of stigma receptivity to pollination. Plant Cell 5:263-275

Keenan RJ, Stemmer WPC (2002) Nontransgenic crops from transgenic plants. Nat Biotechnol 20:215-216

Khan MS, Maliga P (1999) Fluorescent antibioyic resistance marker for tracking plastid transformation in higher plants. Nat Biotechnol 17:910-915

Kobayashi K, Munemura I, Hinata K, Yamamura S (2006) Bisexual sterility conferred by the differential expression of Barnase and Barstar: a simple and efficient method of transgene containment. Plant Cell Rep 25:1347-1354

Kumar S, Dhingra A, Daniell H (2004a) Plastid-expressed betaine aldehyde dehydrogenase gene in carrot cultured cells, roots, and leaves confers enhanced salt tolerance. Plant Physiol 136:28432854

Kumar S, Dhingra A, Daniell H (2004b) Stable transformation of the cotton plastid genome and maternal inheritance of transgenes. Plant Mol Biol 56:203-216

Kuvshinov V, Koivu K, Kanerva A, Pehu E (2001) Molecular control of transgene escape from genetically modified plants. Plant Sci 160:517-522

Lännenpää M, Hassinen M, Ranki A, Holtta-Vuori M, Lemmetyinen J, Keinonen K, Sopanen T (2005a) Prevention of flower development in birth and other plants using a BpFULL1::BARNASE construct. Plant Cell Rep 24:69-78

Lännenpää M, Parkkinen S, Järvinen P, Lemmetyinen J, Vepsäläinen S, Savola T, Keinonen K, Keinänen M, Sopanen T (2005b) The expression and promoter specificity of the birch homologs for PISTILLATA/GLOBOSA and APETALA3/DEFICIENS. Physiol Plant 125:268-280

Lee H-S, Huang S, Kao T-H (1994) S proteins control rejection of incompatible pollen in Petunia inflata. Nature 367:560-563

Lemmetyinen J, Keinonen K, Sopanen T (2004) Prevention of the flowering of a tree, silver birch. Mol Breed 13:243-249

Lemmetyinen J, Pennanen T, Lännenpää M, Sopanen T (2001) Prevention of flower formation in dicotyledons. Mol Breed 7:341-350

Li Y, Chang Z, Smith WA, Ellis DR, Chen Y, Zheng X, Pei Y, Luo K, Zhao D, Yao Q, Duan H, Li Q (2004) Invasive ornamental plants: problems, challenges, and molecular tools to neutralize their invasiveness. Crit Rev Plant Sci 23:381-389
Liu Z, Franks RG, Klink VP (2000) Regulation of marginal tissue formation by LEUNIG and AINTEGUMENTA. Plant Cell 12:1879-1892

Luo K, Duan H, Zhao D, Zheng X, Deng W, Chen Y, Steward CN, McAvoy R, Jiang X, Wu Y, He A, Pei Y, Li Y (2007) "GMgene-deletor": fused $\operatorname{Lox} P-F R T$ recognition sequences dramatically improve the efficiency of FLP or Cre recombinase on transgene excision from pollen and seed of tobacco plants. Plant Biotechnol J 5:263-274

Mariani C, DeBeuckeleer M, Trueltner J, Leemans J, Goldberg RB (1990) Induction of male sterility in plants by a chimeric ribonuclease gene. Nature 347:737-741

Mariani C, Gossele V, Beuckeleer MD, Block MD, Goldburg RB, Greef WD, Leemans J (1992) A chimaeric ribonuclease-inhibitor gene restores fertility to male sterile plants. Nature 357:384-387

Mikkelsen TR, Andersen B, Jorgensen RB (1996) The risk of crop transgene spread. Nature 380:31-31

Nasrallah JB, Nasrallah ME (1993) Pollen-stigma signaling in the sporophytic self-incompatibility response. Plant Cell 5:13251335

Nasrallah JB, Yu S-M, Nasrallah ME (1988) Self-imcompatibility genes of Brassica oleracea: expression, isolation and structure. Proc Natl Acad Sci 85:5551-5555

Nilsson O, Wu E, Wolfe DS, Weigel D (1998) Genetic ablation of flowers in transgenic Arabidopsis. Plant J 15:799-804

Palmiter RD, Behringer RR, Quaife CJ, Maxwell FM, Maxwell IH, Brinster RL (1987) Cell lineage ablation in transgenic mice by cell-specific expression of a toxin gene. Cell 50:435-443

Roeder AHK, Ferrandize C, Yanofsky MF (2003) The role of the REPLUMLESS homeodomain protein in pattering the Arabidopsis fruit. Curr Biol 13:1630-1635

Ruf S, Hermann M, Berger IJ, Carrer H, Bock R (2001) Stable genetic transformation of tomato plastids-high-level foreign protein expression in fruit. Nat Biotechnol 19:870-875

Savidge B, Rounsley SD, Yanofsky MF (1995) Temporal relationship between the transcription of two Arabidopsis MADS box genes and the floral organ identity genes. Plant Cell 7:721-733

Skinner JS, Meilan R, Ma C, Strauss SH (2003) The Pupulus PTD promoter imparts floral-predominant expression and enables high levels of floral-organ ablation in Pupulus, Nicotiana and Arabidopsis. Mol Breed 12:119-132

Snow AA (2002) Transgenic crops-why gene flow matters. Nat Biotechnol 20:542-542

Snow AA, Palma PM (1997) Commercialization of transgenic plants: potential ecological risks. Bioscience 47:86-96

Thorsness MK, Kandasamy MK, Nasrallah ME, Nasrallah JB (1993) Genetic ablation of floral cells in Arabidopsis. Plant Cell 5:253261

Twell D (1995) Diphtheria toxin-mediated cell ablation in developing pollen: vegetative cell ablation blocks generative cell migration. Protoplasma 187:144-154

Wei H, Meilan R, Brunner AM, Skinner JS, Ma K, Gandhi HT, Strauss SH (2007) Field trial detects incomplete barstar attenuation of vegetative cytotoxicity in Populus trees containing a poplar $L E A F Y$ promoter::barnase sterility transgene. Mol Breed 19:69-85

Weigel D, Ahn JH, Blazquez MA, Borevitz JO, Christensen SK, Fankhauser C, Ferrandiz C, Kardailsky I, Malancharuvil EJ, Neff MM, Nguyen JT, Sato S, Wang Z-Y, Xia J, Dixon RA, Harrison MJ, Lamb CJ, Yanofsky MF, Chory J (2000) Activation tagging in Arabidopsis. Plant Physiol 122:1003-1013 